\title{
Near-total lower lip reconstruction: combined Karapandzic and Bernard-Burrow-Webster flap
}

\author{
Manuel António Campos ${ }^{1,2,3,4}$, Paulo Varela ${ }^{1}$, Carlos Marques 5
}

\begin{abstract}
Lip carcinoma is a common cancer of the head and neck region. It more often affects the lower lip (> 90\%), and squamous cell carcinoma represents $95 \%$ of the cases. The authors present a reconstruction of the lower lip combining two classical flaps: the Karapandzic and Bernard-Burrow-Webster flap. The surgical technique is discussed.
\end{abstract}

Keywords: dermatologic surgery, Karapandzic flap, Bernard-Webster flap, lower lip reconstruction

Received: 30 October 2016 | Returned for modification: 22 November 2016 | Accepted: 3 January 2017

\section{Introduction}

Lip carcinoma is a common cancer of the head and neck region. It more often affects the lower lip (>90\%), and squamous cell carcinoma (SCC) represents $95 \%$ of the cases (1-3). In the head and neck region, SCC of the lip is second only to skin cancer in terms of frequency, with an estimated incidence of 0.4 per 100,000 people annualy $(3,4)$. SCC of the lip is more common in men than women (male-to-female ratio of $4: 1)(3,5)$. The gold standard is surgical resection with wide local excision of the primary lesion with negative margins (6). The reconstruction procedure is challenging for surgeons because they have to balance aesthetic appearance with proper function of the oral sphincter and adequate histologic margins. More than 100 procedures for lip reconstruction have been described (1, 7-10). When choosing among these techniques, one must consider the size of the defect, the availability of adjacent tissue, and involvement of the commissures. Lower lip defects can be broken down into three groups: involvement of one-third, one-third to two-thirds, and more than two-thirds of the lip. Defects of more than two-thirds of the lower lip may be preferentially closed with the Karapandzic or Bernard-BurrowWebster flap.

Karapandzic was the first to introduce innervated musculocutaneous flaps that provided immediate postoperative functionality (11). The Bernard-Webster flap is used to reconstruct large lower lip defects with preservation of the commissures by advancing cheek tissue and the remaining lip tissue medially $(12,13)$. In the last 20 years, few surgical techniques have been created, although many authors have modified or combined existing procedures (14).

\section{Case report}

Our case involves an 84-year-old Caucasian male, a smoker since the age of 20 (40 units-pack-year) and with moderate alcohol consumption. Physical examination revealed the presence of a vegetating, ill-defined plaque, with irregular borders and an eroded surface, occupying $85 \%$ of the lower lip (Fig. I-A). According to the patient, the lesion had been present for approximately 6 months. No palpable regional adenopathy was noted. Head and neck ultrasound and CT scan did not reveal nodal metastases. Incisional biopsy confirmed the diagnosis of cutaneous squamous cell carcinoma (cSCC) (T2NoMo).

We performed radical surgical excision of the lesion, resulting in a full-thickness defect with preservation of only $10 \%$ of the lower lip near the left commissure (Fig. I-B). The surgical specimen revealed a moderately differentiated squamous cell carcinoma with clear margins ( $8 \mathrm{~mm}$ from the lateral margin and $10 \mathrm{~mm}$ from the deep margin). No perineural or vascular invasion was observed. Reconstruction was performed upon this extensive lesion using a combination of two well-established and effective flaps for reconstructing the lower lip: the Karapandzic and BernardBurrow-Webster flap. On the left side, we drew the Karapandzic flap, which extended between the inferior border of the excision margins and along the mentolabial and nasolabial crease (Fig. I-B). We incised the Karapandzic flap and freed the orbicularis oris muscle from the neurovascular structures, allowing the rotation of the myocutaneous flap medially. On the right side, because there was no preserved lip, we drew the Webster flap, with two parallel lines on the superior and inferior excision margins and two curvilinear Burrow triangles superiorly and inferiorly (Fig. I-B). The Webster flap was also incised. The Burrow triangle along the nasolabial crease was excised, preserving the deepest mucosa layer. The mucosa of the superior triangle was incised to create a mucosal flap. The mucosal flap was then medially mobilized and approached to the upper border of the myocutaneous flap in order to reconstruct the vermillion border. Both flaps were medially approached and closed in three successive layers (mucosa, orbicularis oris, and skin) in a tension-free manner. With the combination of these flaps we were able to preserve the orbicularis oris and thus the function of the oral sphincter (Figs. I-C and I-D).

The cosmetic and functional result was very satisfactory. The sutures respected the anatomic units of the face and we were able to preserve oral sphincter function. The case was discussed in a multidisciplinary meeting and it was decided that there was no indication for adjuvant radiotherapy or lymph node dissection. After 5 months of follow-up, very slight microstomia was noted, but with no functional impact according to the patient (Figs. I-E and I-F). During the last year, the patient has been examined twice at our department with no sign of recurrence or metastases. 

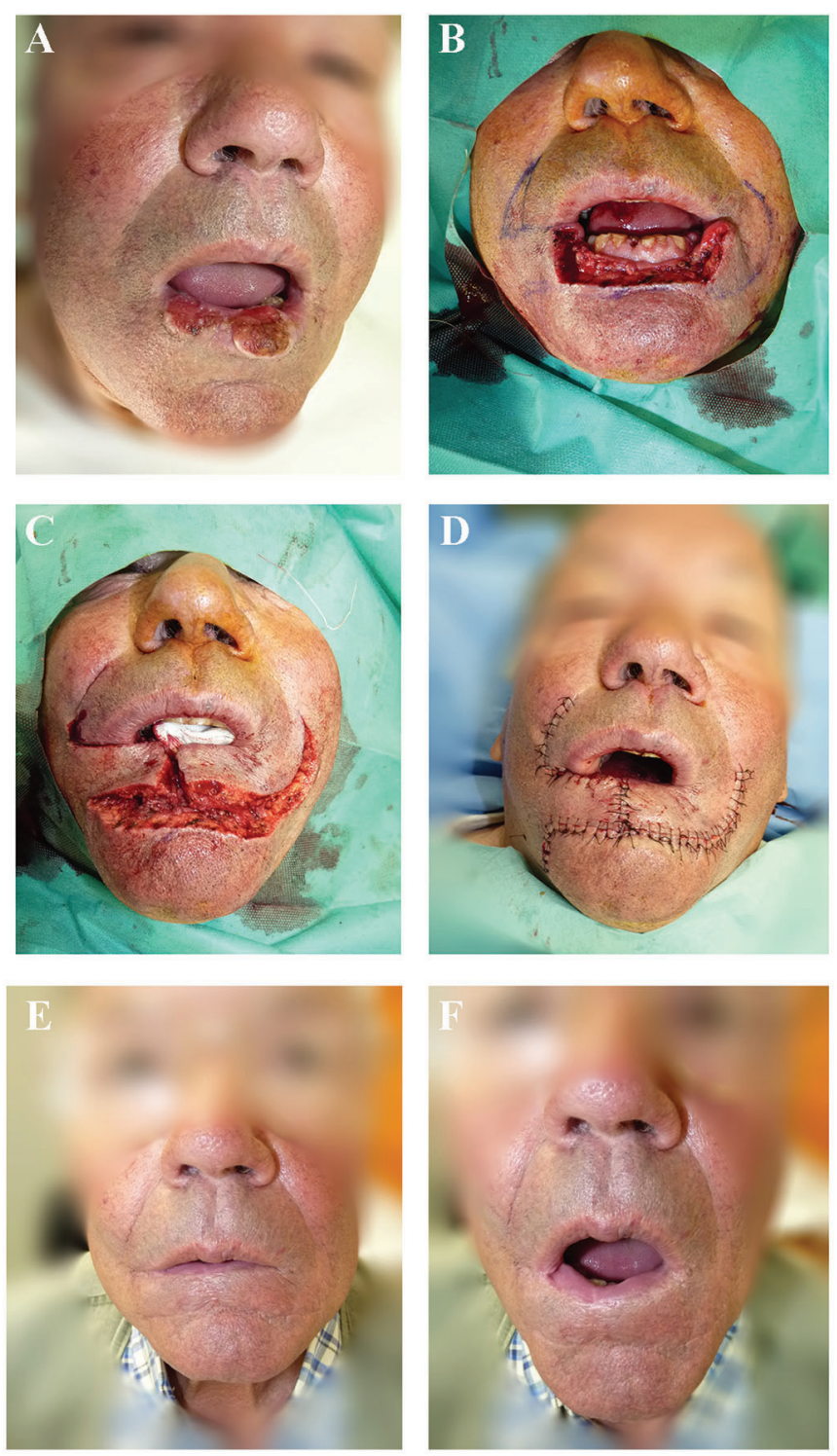

Figure 1 | A: squamous cell carcinoma of the lower lip; B: Excision of the tumor and drawing of the flap; $\mathrm{C}$ : Incision of the flap and excision of the Burrow triangles; D: After deep and superficial closure; E and F: Five-month follow-up.

\section{Discussion}

The Karapandzic flap (11) and the Bernard-Burrow-Webster flap $(12,13)$ are two well-known surgical techniques for the reconstruction of the lower lip. Each of these flaps has advantages and disadvantages. By combining both flaps, we can take advantage of the preservation of the sensibility and motility of the lower lip given by the Karapandzic flap and take advantage of the larger side mobilization of the Webster flap, especially because the lip defect occupied about $90 \%$ of the lower lip. Based on the senior author's experience (CM), if we had chosen to perform a Karapandzic flap bilaterally the resulting microstomia could had been functionally limiting. On the other hand, if we had chosen to perform a bilateral Webster flap, some incontinence of the oral sphincter would probably had occurred. Both of these flaps have the advantage of offering complete immediate functionality (15). It is important to start with the Karapandzic flap in order to determine the degree of advancement required for the Bernard-Webster component. Although we performed a labiomandibular triangle to remove redundant skin, there have been reports that damage of innervation to the depressor anguli oris may occur, and so attention must be applied (14).

We believe that the combination of these flaps is an excellent option for the reconstruction of large lower lip defects (> 80\%) with very satisfactory aesthetic and functional results.

\section{References}

1. Zitsch RP, 3rd. Carcinoma of the lip. Otolaryngol Clin North Am. 1993;26:265-77.

2. Dediol E, Luksic I, Virag M. Treatment of squamous cell carcinoma of the lip. Coll Antropol. 2008;32(Suppl 2):199-202.

3. Casal D, Carmo L, Melancia T, Zagalo C, Cid O, Rosa-Santos J. Lip cancer: a 5-year review in a tertiary referral centre. J Plast Reconstr Aesthet Surg. 2010;63:2040-5.

4. Monteiro LS, Antunes L, Bento MJ, Warnakulasuriya S. Incidence rates and trends of lip, oral and oro-pharyngeal cancers in Portugal. J Oral Pathol Med. 2013;42:345-51.

5. Han AY, Kuan EC, Mallen-St Clair J, Alonso JE, Arshi A, St John MA. Epidemiology of squamous cell carcinoma of the lip in the United States: a population-based cohort analysis. JAMA Otolaryngol Head Neck Surg. 2016;142:1216-23.

6. Belcher R, Hayes K, Fedewa S, Chen AY. Current treatment of head and neck squamous cell cancer. J Surg Oncol. 2014;110:551-74.

7. Closmann JJ, Pogrel MA, Schmidt BL. Reconstruction of perioral defects following resection for oral squamous cell carcinoma. J Oral Maxillofac Surg. 2006;64:367-74.

8. Constantinidis J, Federspil P, Iro H. Die funktionell und ästhetisch orientierte Rekonstruktion von Lippendefekten [Functional and esthetically oriented reconstruction of lip defects]. HNO. 2000;48:517-26. German.

9. Coppit GL, Lin DT, Burkey BB. Current concepts in lip reconstruction. Curr Opin Otolaryngol Head Neck Surg. 2004;12:281-7.

10. Brinca A, Andrade P, Vieira R, Figueiredo A. Karapandzic flap and BernardBurrow-Webster flap for reconstruction of the lower lip. An Bras Dermatol. 2011;86(Suppl 1):S156-9.

11. Karapandzic M. Reconstruction of lip defects by local arterial flaps. Br J Plast Surg. 1974;27:93-7.

12. Webster RC, Coffey RJ, Kelleher RE. Total and partial reconstruction of the lower lip with innervated musclebearing flaps. Plast Reconstr Surg Transplant Bull. 1960;25:360-71.

13. Bernard C. Cancer de la lèvre inférieure: Restauration à l'aide de lembeaux quadrilataires-latéraux [Cancer of the lower lip: restoration with the help of quadrilateral-lateral flaps]. Scalpel. 1852;5:162-4. French.

14. Westreich R, Meisner J, Reino A, Lawson W. The use of combined Bernard-Webster and Karapandzic flaps for subtotal lower lip reconstruction. Plast Reconstruct Surg. 2008;121:340e-1e.

15. Wechselberger G, Gurunluoglu R, Bauer T, Piza-Katzer H, Schoeller T. Functional lower lip reconstruction with bilateral cheek advancement flaps: revisitation of Webster method with a minor modification in the technique. Aesthet Plast Surgery. 2002;26:423-8. 